\title{
Hydrophilic Polysiloxane Microspheres and Ceramic SiOC Microspheres Derived from Them
}

\author{
J. Chojnowski ${ }^{1}$ - S. Slomkowski ${ }^{1}$ 'W. Fortuniak ${ }^{1} \cdot$ U. Mizerska ${ }^{1} \cdot$ P. Pospiech $^{1}$
}

Received: 19 June 2019 / Accepted: 3 August 2019 / Published online: 25 October 2019

(c) The Author(s) 2019

\begin{abstract}
In this overview article, the research on polysiloxane microspheres performed in the authors' laboratory is briefly reviewed. These microspheres are prepared in water emulsion from polyhydromethylsiloxane (PHMS). This polymer is cross-linked in the emulsion process by hydrosilylation using various low molecular weight cross-linkers having at least two vinyl functions. The microspheres contain a large number of silanol groups which give them hydrophilicity and a broad possibility of functionalization by condensation with reactive silanes bearing a functional group in the organic radical. Further transformation of these functions leads to materials for practical use, such as catalysts and biocidal powders. The hydrophilic-hydrophobic properties of the microspheres may be fine-tuned by silylation or modification of the precursor PHMS polymer. Pristine microspheres are highly hydrophilic and well-dispersed in water. They do not adsorb proteins and hydrophobic organic substances. Macropores may be generated in these particles by a simple modification of the emulsion procedure. These microspheres are also very good precursors for ceramic silicon oxycarbide microsphers because they retain their shape in pyrolytic processes even at high temperatures; and they give a high yield of ceramic material. The polysiloxane microspheres heated at $600{ }^{\circ} \mathrm{C}$ give micro and mezo porous materials with specific surface above $500 \mathrm{~m}^{2} / \mathrm{g}$. When pyrolysed at temperatures $1000-1400{ }^{\circ} \mathrm{C}$, they form solid ceramic microspheres of high strength. They retain spherical shape at $1500{ }^{\circ} \mathrm{C}$ although cracks are formed at their surfaces. Etching them with $\mathrm{HF}(\mathrm{aq})$ solution gives porous microspheres with specific surface above $1000 \mathrm{~m}^{2} / \mathrm{g}$ that is almost devoid of $\mathrm{SiO}_{2}$.
\end{abstract}

Keywords Polysiloxane microspheres $\cdot$ Hydrophilic polysiloxane $\cdot$ Functional microspheres $\cdot$ Silicon oxycarbide microspheres $\cdot$ Porous microspheres $\cdot$ Polysiloxane derived ceramics

\section{Introduction}

Microspheres are spherical particles with a range of diameter from 0.1 to $200 \mu \mathrm{m}$ and have many types of topologies and diverse chemical structures. Polymer microspheres are a broad area of research, which has been the subject of many review papers, e.g. [1-5]. Thousands of articles

This paper is dedicated to Professor Martel Zeldin Founder and the First Editor-in-Chief of Journal of Inorganic and Organometallic Polymers currently Journal of Inorganic and Organometallic Polymers and Materials on the occasion of the 30th Anniversary of the Foundation of this Journal.

J. Chojnowski

jchojnow@cbmm.lodz.pl

1 Center of Molecular and Macromolecular Studies, Polish Academy of Sciences, 112 Sienkiewicza, 90-363 Lodz, Poland are devoted to the description of methods of their generation and their applications in areas of medical science and technology. Among them, polysiloxane microspheres occupy important position due to some unusual properties that make them desirable materials for many applications. Polysiloxanes themselves are known for their thermal and chemical stability, interesting reological and surface properties, and appropriate optical and dielectrical characteristics. In addition, they may be easily modified and are available at moderate prices [6]. Polysiloxane microspheres are commonly used in medicine and biology for drug delivery systems [7, 8], biological probes and biosensors [9], carrier of proteins [10], supports in enzymatic catalysis [11], and carriers of biocides [12]. They are exploited in the catalysis of various chemical reactions $[13,14]$ and as components of composite materials [15]. The synthesis and use of polysiloxane microspheres of various morphologies and chemical structures have been the subject of extensive research devoted 
Scheme 1 Fabrication of hydrophilic microspheres

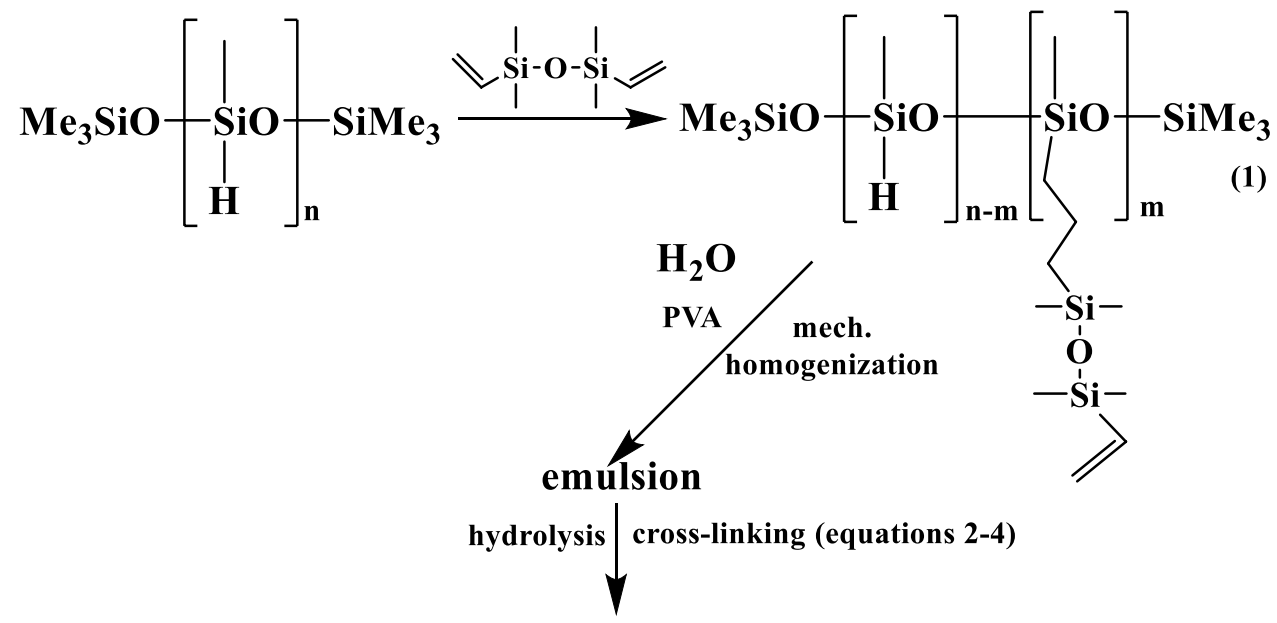

to polysiloxane core-shell [16, 17], hollowed [18, 19] and porous [17] microspheres as well as to beads containing other materials dispersed or dissolved in polysiloxane matrixes [20, 21]. The present overview is limited to specific kinds of polysiloxane microspheres, which were obtained from polyhydromethylsiloxanes developed in our laboratory. Their distinctive features are large number of reactive silanol groups that render them hydrophilic and easy their facile functionalization. They are also excellent precursors of ceramic silicon oxycarbide.

\section{Synthesis of Hydrophilic Polysiloxane Microsphers}

Water emulsion processes are common methods of generation of polymer microspheres [2, 3]. These microspheres may be formed either by emulsion polymerization processes or emulsification of polymer solutions. Although the first method leads to particles of unified sizes, the latter method, which has been used in this research, is simpler and inexpensive. The precursors that are used are commercial linear polyhydromethylsiloxanes (PHMS) with molar mass from 2000 to 3000 and terminated with trimethylsiloxy units. These polymers are cross-linked in an aqueous emulsion process by hydrosilylation with their $\mathrm{SiH}$ groups of low molecular weight compounds that have at least two vinyl functions [22]. The most often used cross-linker is

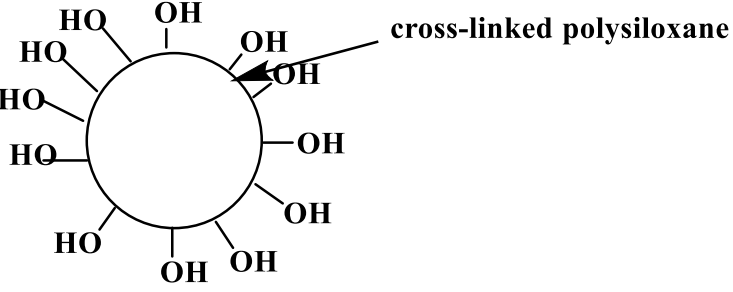

hydrophilic microsphere

1,3-divinyltetramethyldisiloxane (TVMDS) and the catalyst is an active concentrated solution of $\operatorname{Pt}(0)$ Karstedt complex. Since hydrosilylation in water emulsion proceeds with difficulty [23], the first stage of this reaction is carried out in a water miscible solvent such as dioxane or tetrahydrofurane. It leads to partial grafting usually about $60 \%$, of the crosslinker on the polymer chain (Eq. 1, Scheme 1). The time for this first step of hydrosilylation must be strictly controlled to prevent cross-linking [22].

Polysiloxanes modified in this way and containing the catalyst are emulsified with a limited amount of water and surfactant such as poly(vinyl alcohol) (PVA). Addition of isopropanol before the homogenization may improve the formation of microspheres. The emulsification is performed mechanically in a homogenizer, usually for $0.5-3 \mathrm{~min}$ at 5000-10,000 rpm. The formed emulsion is diluted with a larger amount of water containing PVA. Further process of the microsphere consolidation is performed in a diluted emulsion at elevated temperature with gentle mixing for several dozen hours (Scheme 1). Using this process, further hydrosililation occurs, which forms bridges that link polysiloxane chains (Eq. 2). This is accompanied by two additional reactions that are catalyzed by the $\operatorname{Pt}(0)$ complex; one is the hydrolysis of $\mathrm{SiH}$ that transforms these groups into silanol units (Eq. 3), and the other is condensation of some of the $\mathrm{SiOH}$ groups that are formed in the hydrolysis of $\mathrm{SiH}$. The latter forms siloxane bridges and enhances polysiloxane cross-linking (Eq. 4) [22, 24]. 


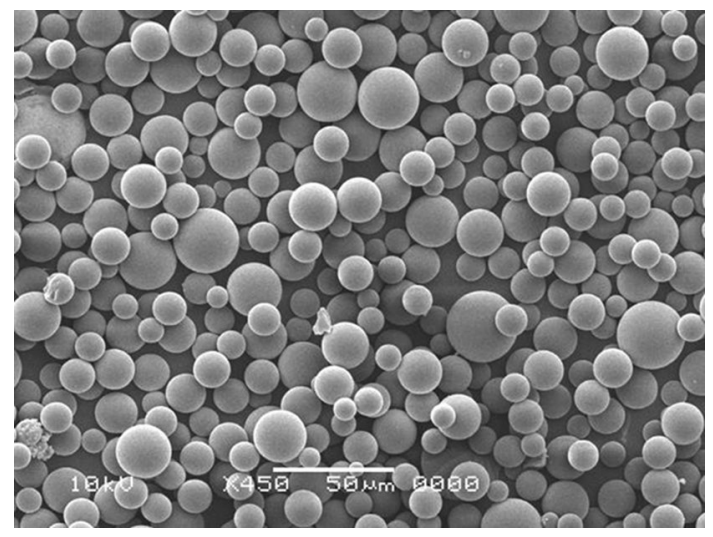

Fig. 1 SEM image of the hydrophilic polysiloxane microspheres

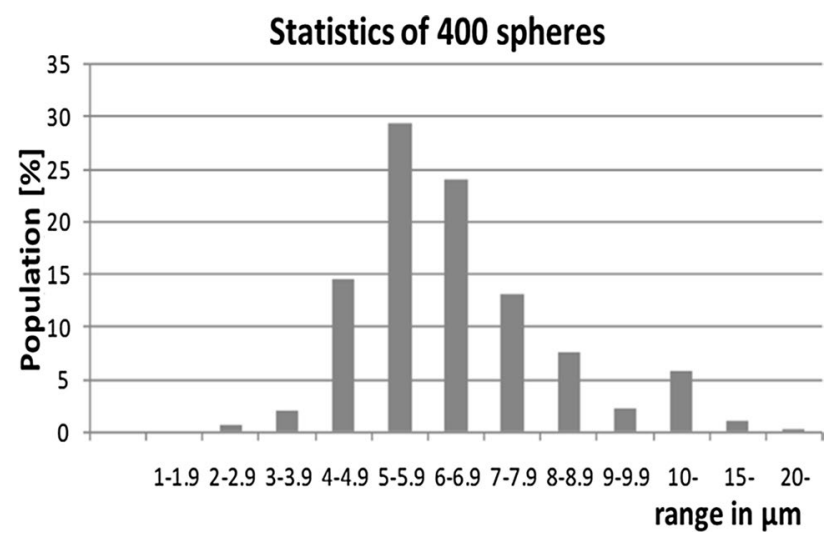

Fig. 2 Example of the size dispersion of polysiloxane microspheres, hydrophylic polysiloxane microspheres

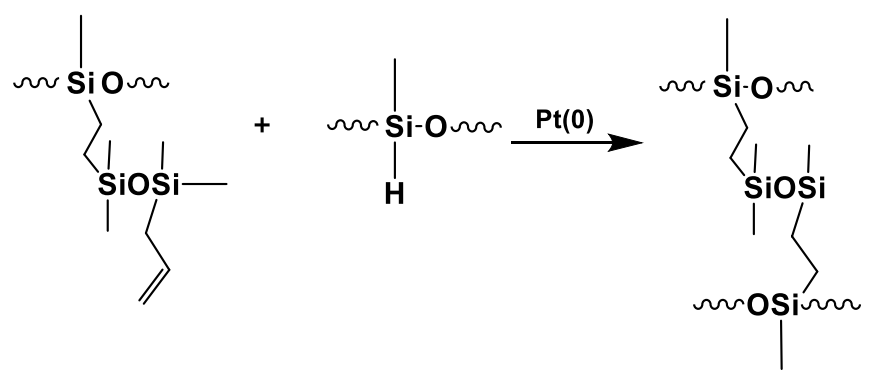<smiles>C[Si](C)(O)O[Mg]</smiles>

Table 1 The dependence of the average size of microspheres on the rate and time of stirring in emulsification by MPW-120 homogenizer and on the concentration of PAV

\begin{tabular}{llll}
\hline $\begin{array}{l}\text { Rate of stir- } \\
\text { ring }(\mathrm{rpm})\end{array}$ & $\begin{array}{l}\text { Time of stir- } \\
\text { ring }(\mathrm{s})\end{array}$ & $\begin{array}{l}\text { PAV }(\mathrm{g} / 100 \mathrm{~mL} \\
\text { of water })\end{array}$ & $\begin{array}{l}\text { Average diameter of } \\
\text { microspheres }(\mu \mathrm{m})\end{array}$ \\
\hline 3000 & 30 & 0.41 & 36 \\
5000 & 30 & 0.41 & 15.8 \\
7500 & 30 & 0.41 & 6.4 \\
15,000 & 30 & 0.41 & 2.3 \\
7500 & 30 & 0.25 & 6.8 \\
7500 & 30 & 0.83 & 6.8 \\
7500 & 180 & 0.41 & 3.2 \\
15,000 & 180 & 0.41 & 1.4 \\
\hline
\end{tabular}

Data were selected from Ref. [22]. Reaction conditions: $6.0 \mathrm{~g}$ of PHMS, $1.2 \mathrm{~g}$ DVTMDS in $10 \mathrm{~mL}$ of dioxane, $2 \times 10^{-7} \mathrm{~mol} / \mathrm{g}_{\text {polysiloxane }}$ of $\mathrm{Pt}, 45^{\circ} \mathrm{C}$, preliminary hydrosilylation for $9 \mathrm{~min}, 10 \mathrm{~mL}$ of dioxane added, homogenization with $100 \mathrm{~mL}$ of water at $45^{\circ} \mathrm{C}$, dilution with $300 \mathrm{~mL}$ of water, further hydrosilylation for $48 \mathrm{~h}$ at $45^{\circ} \mathrm{C}$

The SEM microgram (Fig. 1) represents typical microspheres formed in this process. The microspheres show dispersion of size, an example of which is seen in Fig. 2. The average diameter of these particles ranges from 2 to $40 \mu \mathrm{m}$ and depends on the conditions of the homogenization process [22]. The time and speed of stirring in the homogenization process has a large impact on microsphere size while the content of the emulsifier seems to play minor role (Table 1).

The hydrolysis process occurs fast and converts up to $80 \%$ of $\mathrm{SiH}$ groups in the polysiloxane precursor into silanol groups thus making the microspheres highly hydrophilic. ${ }^{29} \mathrm{Si}$ MAS NMR spectroscopy screens well the chemical structure of these microspheres (Fig. 3). 


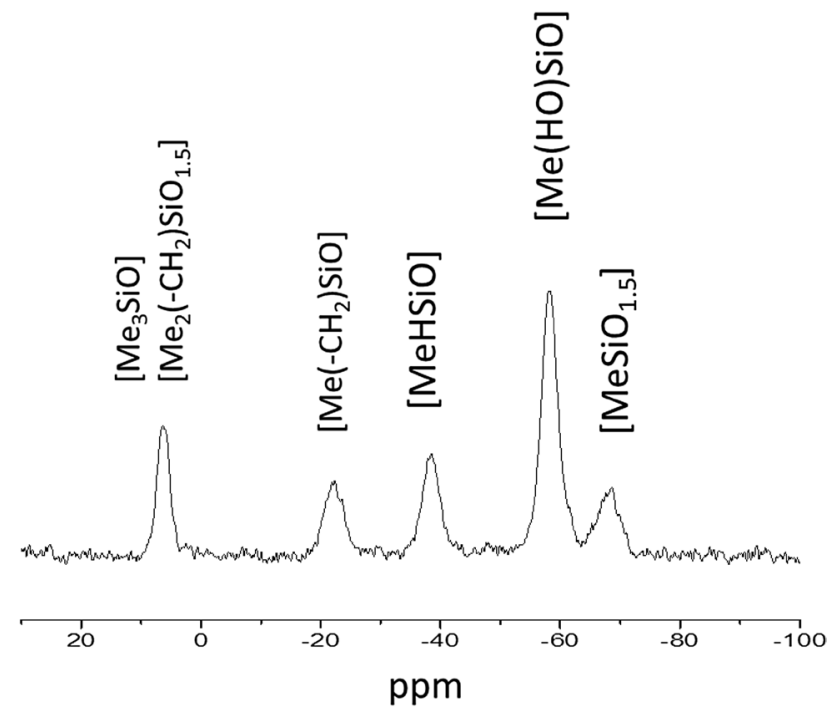

Fig. $3{ }^{29}$ Si MAS NMR of hydrophilic polysiloxane microspheres

In the spectrum of the precursor polysiloxane, in addition to a small signal assigned to the end groups, only one strong peak appears at $-38 \mathrm{ppm}$ that is assigned to silicon bonded to hydrogen. This signal is strongly reduced in the spectrum of the microspheres (Fig. 3). However, a dominant signal at $-58 \mathrm{ppm}$ for the silanol group-containing unit is observed. Some of these silanol groups undergo heterocondensation with $\mathrm{SiH}$ to give rise to siloxane bridges (resonance at $-68 \mathrm{ppm}$ ), which together with the bridges formed by hydrosilylation ( $-22 \mathrm{ppm}$ and $+8 \mathrm{ppm}$ ) yield the cross-linked structure that stabilizes the microspheres.

The formation of a large number of silanol groups requires a large quantity of water. Since the molecular mass of the siloxane unit in PHMS is 60 and that of water is 18 , more than $20 \mathrm{w} \%$ of the water in the polymer droplets is needed to form a large number of the silanol groups. How this water gets into the hydrophobic polymer is puzzling. Hypothetically, a slow penetration of water combined with hydrolysis of the subsequent layer of the polymer particle is possible during microsphere consolidation. However, the result of simple experiments contradict this mechanism [25]. Microspheres from one synthetic run were fractionated and analysed. It turned out that the larger microspheres contained more silanol groups that the smaller microspheres, although the hydrosilylation reaction proceeded at the same rate in all the microsphere fractions. Thus, water does not diffuse into, but out of the microspheres. The double emulsion of water/ oil-oil/water is formed during the homogenization process. Each polymer microdroplet in the formed emulsion contains dispersed nanodroplets of water, which is the source of water that is used in $\mathrm{SiH}$ hydrolysis. Water nanodroplets have tendency to escape from the polymer droplets, which is the reason for the failure of attempts to obtain submicron size microspheres that contain a large number of $\mathrm{SiOH}$ groups even by using an ultra high-speed homogenizer.

\section{Functionalization of Hydrophilic Microspheres}

Silanol groups are very reactive in condensation processes with alkoxy and chlorosilanes [26, 27]. This allows for the modification of the microspheres by reactions with these silanes that bearing in addition a functional group in the organic radical [22] (Scheme 2).

These modifications occur not only on the microsphere surface but also within the particle. The structure of microsphere is relatively loose and low molar mass reagents can relatively easily penetrate. The swelling of the microsphere in the reaction solvent may help this penetration. Functionalized organotrialkoksysilanes may be used; however, trichlorosilanes are too reactive. More than one group may enter into the reaction thereby tightning the structure by additional cross-linking, which may cause the disruption of the microspheres. Our research group has introduced into our microspheres many functions, such as olefines, amines, halogens, tiols and some heterocycles (epoxide, imidazole) $[22,28-30]$. An example of these reactions is
Scheme 2 Generation of functionalized polysiloxane microspheres

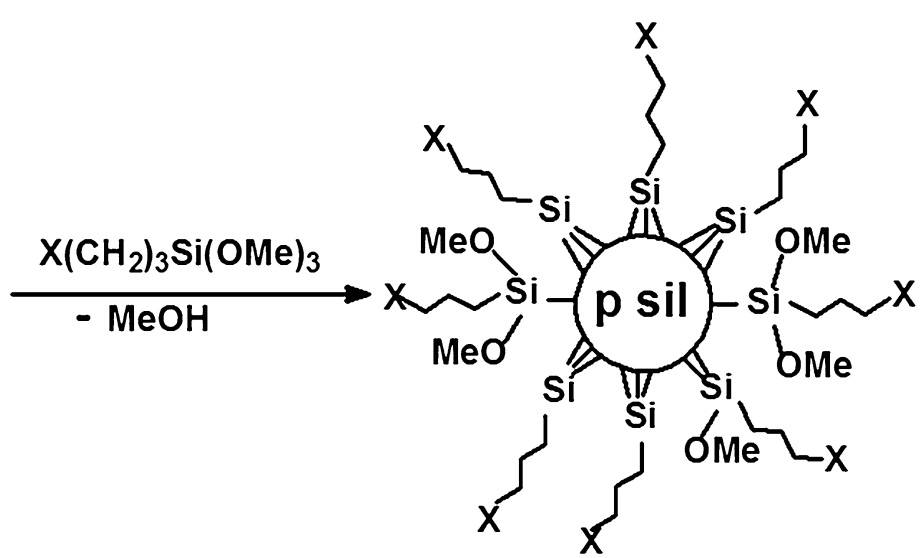


shown in Eq. 5. These groups were further transformed to obtain some products for practical use. For example, imidazole and amine groups bonded to microspheres were used as ligands to obtain complexes of palladium or platinum, which were very active catalysts of olefin hydrogenation, hydrosilylation and Suzuki-Miaura reactions [28, 29, 31]. These catalysts were easily separated from reaction products and further used manyfold in the catalysis of these reactions showing high recyclability. Addition of $\mathrm{Fe}_{3} \mathrm{O}_{4}$ powder to the microspheres gives them magnetic activity, which made easier their separation after catalytic process.
In addition to catalysts, bactericidal powders were obtained [30]. Thus, sulfhydryl groups were introduced to microspheres (Eq. 8) suspended in toluene, which was followed by the reaction with $\mathrm{AgNO}_{3}$ dissolved in acetonitrile catalyzed by butylamine. Microspheres loaded with silver tiolate were obtained. XPS spectroscopy and SEM and TEM<smiles>CCCCO[Si](CCCN)(OCC)O[Si](C)(C)O[Na]</smiles>

The example of the preparation of a transition metal catalyst heterogenized on the polysiloxane microspheres is shown in Eqs. 6 and 7. In this case, $\mathrm{N}$-[ $\gamma$-(dimethylchlorosilyl)propyl]imidazole hydrochloride [32] was subjected to reaction with the silanol groups of the microspheres in a methylene chloride suspension. Further reaction of the formed imidazole functionalized microspheres with a palladium complex, followed by the reduction of the palladium complex heterogenized on microspheres, gave a selective and efficient catalyst for the hydrogenation of cinnamaldehyde [29].<smiles></smiles>

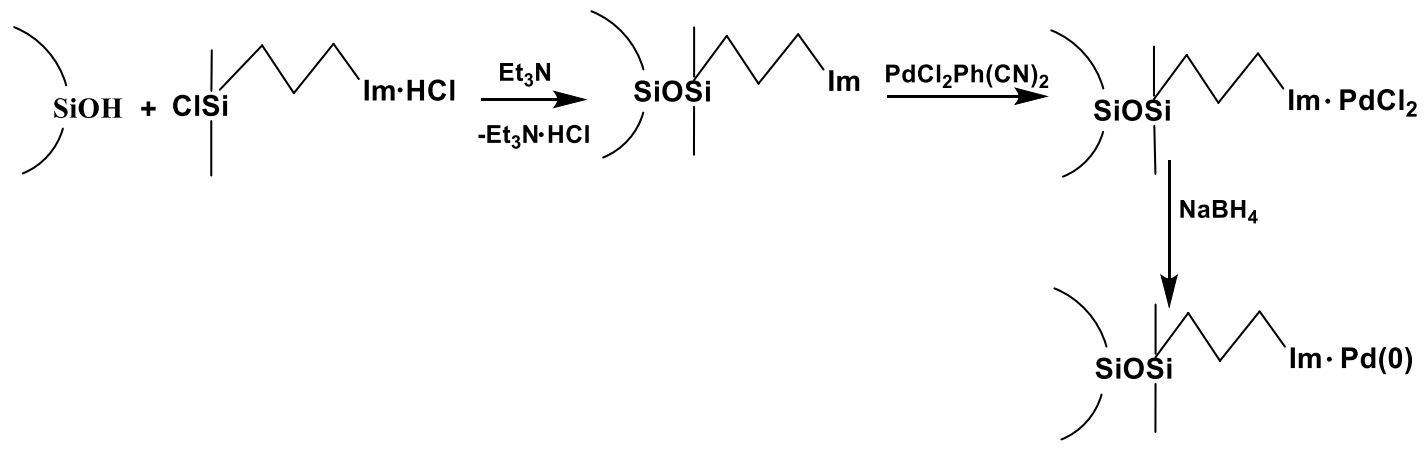


electron microscopy revealed the coexistance of this silver tiolate with nanoparticles but, it does color those modified with hydrophilic ionic groups.
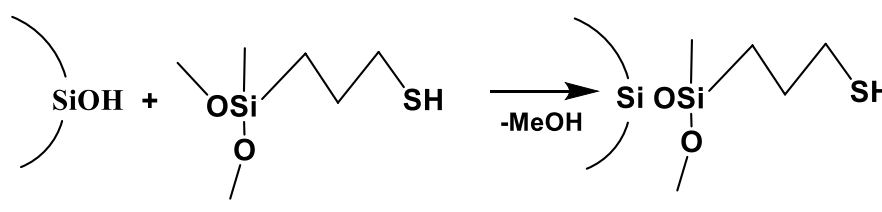

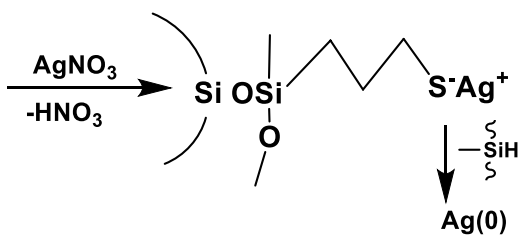

(8)

On the other hand, the controlled adsorption of proteins on polysiloxane surfaces is sometimes desired property for practical use. This is the case in tissue engineering, diagnostic tests, sensors, biocatalysis, and drug delivery [33, 37-39]. The hydrophilic-hydrophobic properties of our microspheres may be tuned by partial silylation with trimethylchlorosilane or trimethylethoxysilane [35]. The reaction with an excess of trimethylchlorosilane changes the microspheres to a highly hydrophobic material, while treating them with small amounts of the silylation agent limits their hydrophilic properties. The other method of fine-tuning the hydrophilicity of the microspheres is the modification of the polysiloxane precursor by the subtitution of a portion of the $\mathrm{SiH}$ groups with alkoxy groups by reaction with alkohol, such as isopopanol, catalyzed by $\mathrm{Pt}(0)$ complex [35] (Eq. 9). be modified by reactants that impart hydrophilic charac ter [33]. A common method for this modification is the

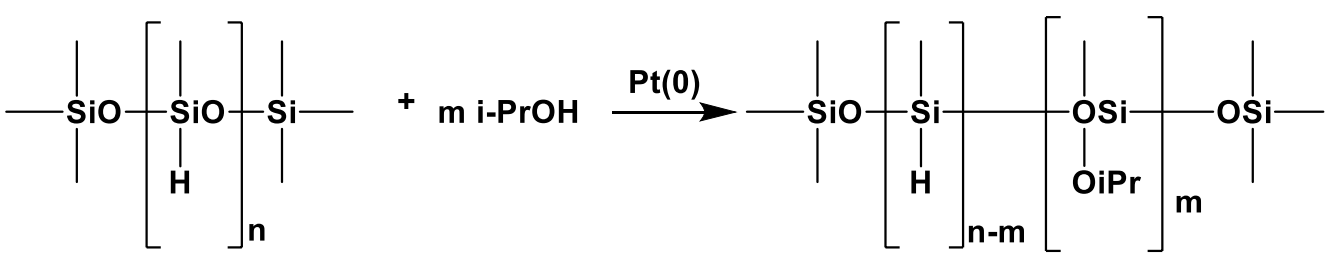

grafting of polyethylene glicol (PEG) onto the polysiloxane surface. The microspheres prepared in our laboratory do not need this modification and could be useful as powders in cosmetics and medicine. Their high hydrophilicity was confirmed by adsorption studies of globulines [34, 35], which are often used as model proteins in the screening of the adsorption ability of surfaces [36]. Isotherms of the adsorption on neat hydrophilic microspheres and on microspheres modified with some polar or ionic groups are displayed in Fig. 4. Unmodified microspheres having only silanol groups do not adsorb globuline, while those having the part of the silanol substituted by ionic hydrophilic groups, such as ammonium or imidazolium, show considerable adsorption of the protein. The reason for this is the interaction of the protein with the modified microspheres by electrostatic forces [33]. Other tests were performed using Bengal Rose dye, which has a great affinity to hydrophobic surfaces and is often used in studies of hydrophilic-hydrophobic properties of surfaces [34]. This dye does not color neat silanol-substituted microspheres,

\section{Generation of Macropores in the Hydrophilic Polysiloxane Microspheres}

The micospheres prepared in our laboratory are cross-linked polysiloxane elastomers that are solids. Generation of pores in such elastomer particles carried out in other laboratories required special methods in their preparation. Thus, macroporous polysiloxane microspheres were produced by using a double emulsion system involving a microfluidic techniqe [40]. A two-step double emulsion technique was also used to obtain spheroidal particles with a size greater than $10 \mathrm{~m} \mu$ [41]. Spheroidal polysilsesquioxane macroporous particles of several hundred micrometers were formed by an electrodynamic method [42]. Another method employed was that based on emulsion-ice templating [43].

We found that minor modifications in the preparation of our microspheres (Scheme 3) generated macropores [25].

The addition of salts, such as $\mathrm{NiCl}_{3} \cdot 6 \mathrm{H}_{2} \mathrm{O}, \mathrm{FeCl}_{3} \cdot 6 \mathrm{H}_{2} \mathrm{O}$, $\mathrm{AgNO}_{3}$ to the precursor before emulsification leads to the 


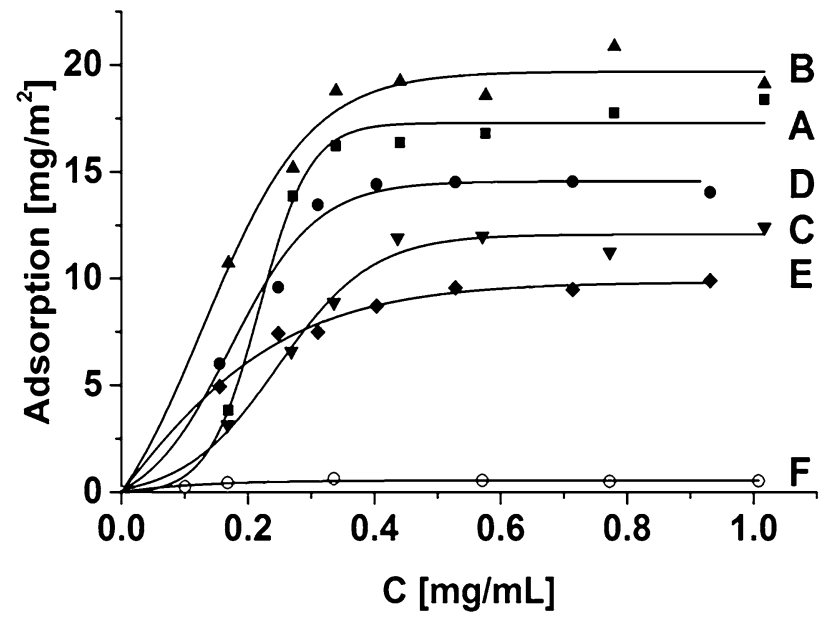

Fig. 4 Adsorption isotherms at $\mathrm{pH} 7.4$ of globulines on non-functionalized and functionalized microspheres, $\mathbf{f}$ non-functionalized, $\mathbf{a}, \mathbf{b}, \mathbf{c}$, d, e functionalized by $\mathrm{OSiMe}_{2}\left(\mathrm{CH}_{2}\right)_{3} \mathrm{X}$ substituted for $\mathrm{OH}$ groups; where $\mathrm{X}$ is: a amine, b $\mathrm{N}$-imidazole, c $\mathrm{N}(\mathrm{N}$-n-octylimidazolio) iodide, d n-octyldimethylammonio chloride, e N(N-methylimidazolio) iodide. Reproduced with permission from Ref. [34]

formation of nanodroplets of the aqueous salt solution dispersed in the polymer emulsion particles in the homogenization process. The transformation of $\mathrm{SiH}$ into $\mathrm{SiOH}$ groups makes the polymeric hydrophilic membrane capable for the penetration of water; i.e., the osmotic pressure forces the water through this membrane into the nanodroplets that contain the salt solution. The pressure is built that forms channels through which the salt solution diffuses out of the microparticle. This usually occurs violently with a deformation of the microsphere (Fig. 5). The formation of macropores occurs gently with the preservation of the microspheric shape when a diluted salt solution is used. An open character of most of the pores was confirmed by a mercury intrusion study [25].

Scheme 3 Generation of macroporous polysiloxane spheroidal particles

\section{Fabrication of Core-Shell Polysiloxane Microcapsules Containing Phase Change Materials (PCM)}

Polysiloxane containing alkyl and hydroxyl group in its siloxane unit behaves as a surfactant in aqueous media and allows the encapsulation of some hydrophobic materials in the polysiloxane shell.

Co-emulsification of the PHMS, modified by the grafting a cross-linker, with n-eicosane dissolved in isopropanol led to the formation of core-shell polysiloxane capsules with a n-eicosane core [44] (Scheme 4). These capsules were distorted microspheres (Fig. 6). Their morphology depended on the conditions of the emulsion process as they show a tendency to form a multicorous structures [45].

n-Paraffines, such as n-eicosane, are commonly used as phase change materials (PCM) applied for thermoregulation and thermal energy storage $[46,47]$. The capsules containing n-eicosane, which have a high latent heat of fusion and a melting point close to the physiological temperature of the human body, are particularly interesting materials for use in the textile industry. If dispersed in cloth, it gives skin the feeling of thermal comfort and protection against thermal shock. Polysiloxanes are also attractive materials for use as a capsule shell because of their physiological neutrality, chemical and thermal stability and resistance to oxygen and water vapor. They could replace materials that are based on carcinogenic formaldehyde. The polysiloxanes are mechanically strong and elastic enough to withstand the volume change during a phase change. Nonwoven textile material that is modified with selected polysiloxane PCM capsules was subjected to thermoregulation studies [48]. The modified textile had good and stable thermoregulating properties and showed a high-energy storage coefficient.

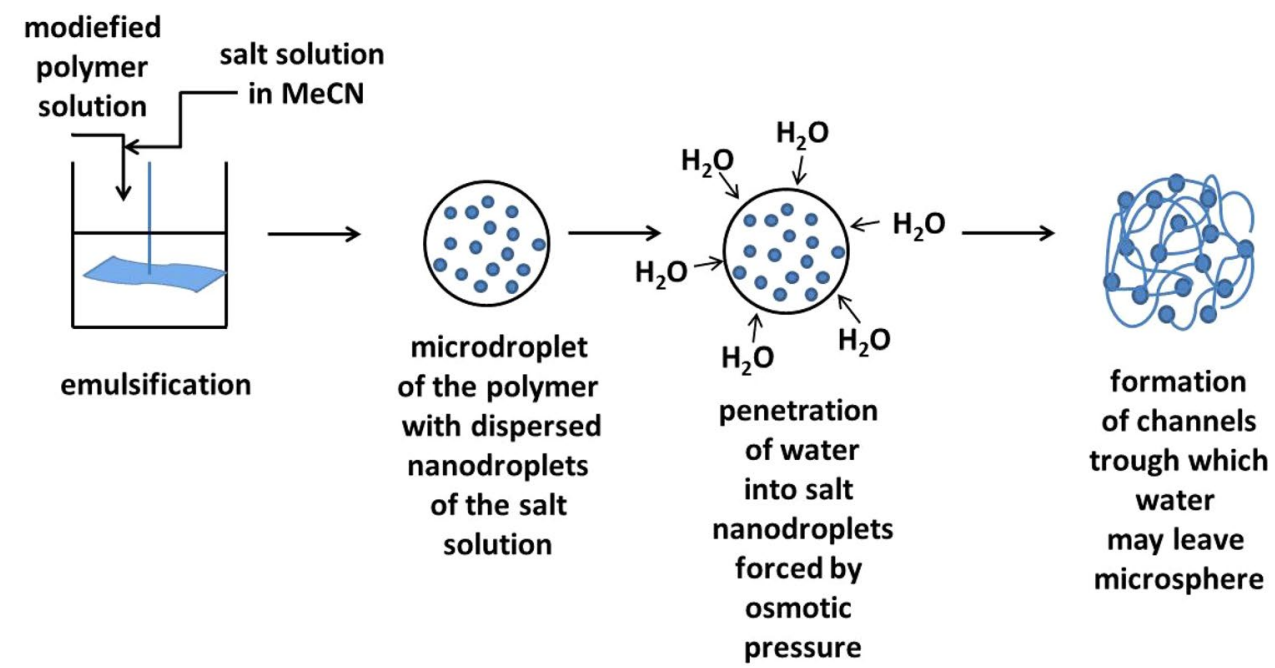



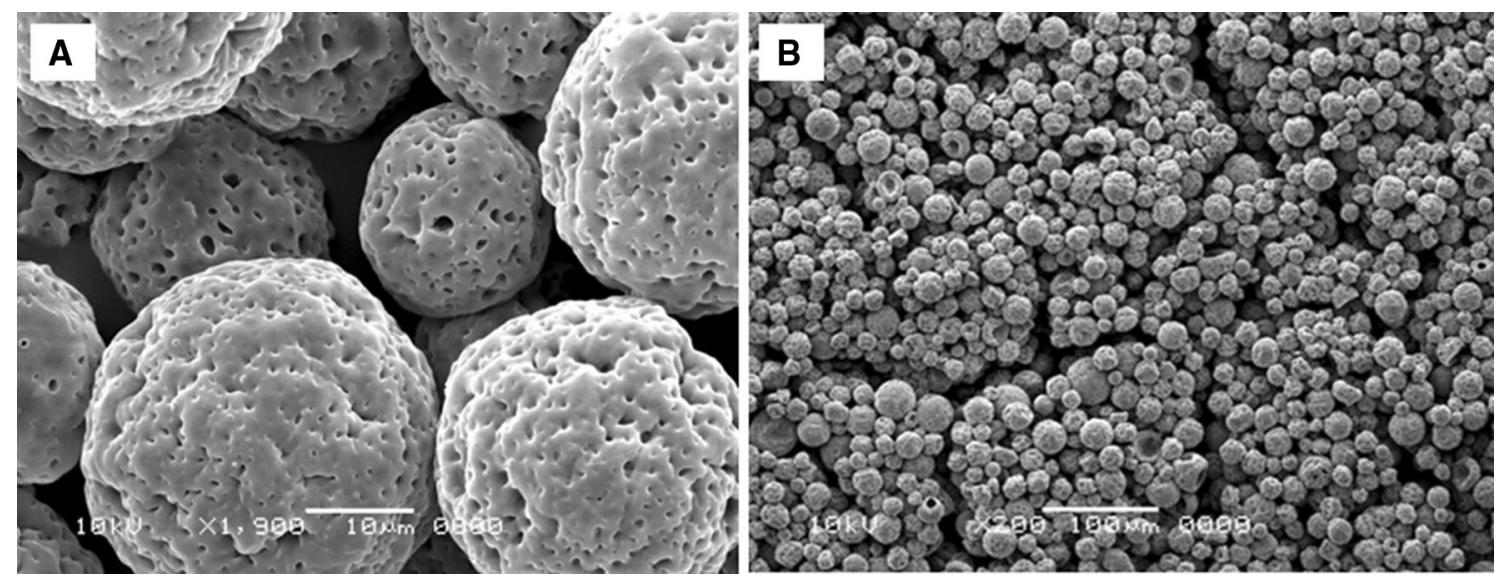

Fig. 5 SEM micrographs of microspheroidal particles obtained with the addition of: a $\mathrm{NiCl}_{2} \cdot 6 \mathrm{H}_{2} \mathrm{O}$, at higher enlargement, $\mathbf{b} \mathrm{FeCl}_{3} \cdot 6 \mathrm{H}_{2} \mathrm{O}$

Scheme 4 Polysiloxane PCM microcapsules formation

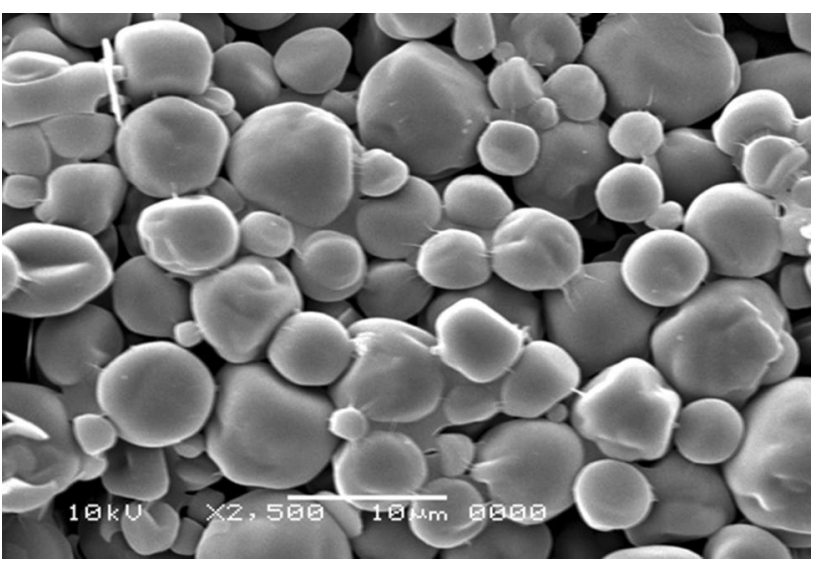

Fig. 6 Polysiloxane capsules with n-eicosane core

\section{Generation of SiOC Ceramic Microspheres}

Silicon-based polymer-derived ceramics have been intensively developed in various laboratories over past 40 years water

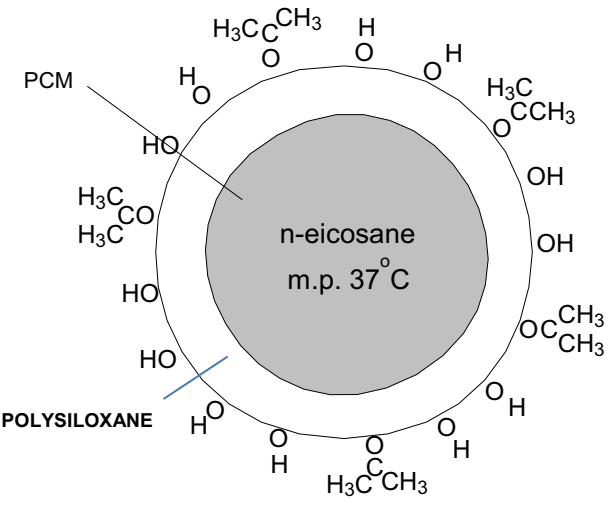

$[49,50]$. Making ceramic products from polymer precursors has many advantages over the classical methods. One of the advantages is the possibility of shaping ceramics on nano and micro scale, which opens the route to ceramic fibers, thin films and specifically shaped regular nano- and microparticles. Amongst the latter, microspheres are gaining particular importance $[49,51]$. They could find application as catalysts for high temperature processes, hot-gas purification, gas separation and generation of composites. The ceramic microspheres develop their shape at the precursor stage. However, the basic problem is the retention of their shape during the ceramization process [51]. The chemical and physical structures of the material are heavily changed during the thermal process and may lead to cracking and disruption of the spherical particles. Very slow temperature increase is required to prevent these phenomena.

Our polysiloxane microspheres are very good precursors for the preparation of ceramic silicon oxycarbide microspheres. Due to the relatively loose structure and the presence of functional groups capable of condensation in elevated temperature, they retain their spherical structure 


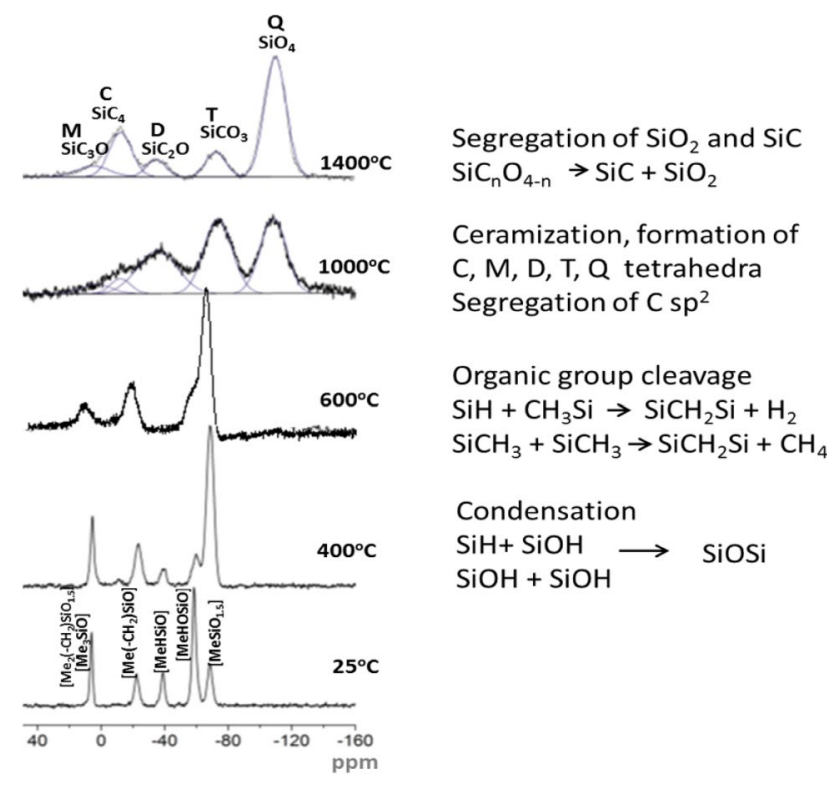

Scheme 5 Variation of ${ }^{29} \mathrm{Si}$ MAS NMR spectra of polysiloxane microspheres pyrolyzed at various temperature

during heating at high temperature and can withstand a high rate of the temperature increase [52, 53]. They do not need a separate cross-linking step. Moreover, since the organic group contribution to their weight is low, the yield of ceramic material is high, in some cases as much as $90 \%$.

Considerable research has been devoted to understanding the chemical and physical processes of polysiloxane ceramization [54-57]. Similar processes occur during heating our materials. We have examined them by ${ }^{29}$ Si MAS NMR spectra, which show the chemical structure evolution during pyrolysis of the polysiloxane microspheres (Scheme 5).

Thus, during heating at $400{ }^{\circ} \mathrm{C}$, homo and hetero-condensation processes occur; i.e., signals of $\mathrm{SiOH}$ and $\mathrm{SiH}$ containing units at -58 and $-38 \mathrm{ppm}$, respectively, decrease while the signal of the units linking the polymer chains by siloxane bridges at $-68 \mathrm{ppm}$ is strongly enhanced. The material becomes harder. Further heating at $600{ }^{\circ} \mathrm{C}$ causes partial cleavage of the organic groups with the formation of gaseous products, mostly methane and hydrogen. The material becomes hard as new carbon and oxycarbon bridges are formed between the polymer chains. The material also becomes porous because the evolution of gaseous products produces micro- and mezopores with specific surface areas up to $550 \mathrm{~m}^{2} / \mathrm{g}$. It is not a ceramic material since the ${ }^{29} \mathrm{Si}$ MAS spectrum is typical for a polymer. Such a material is called a ceramer [58]. True SiOC ceramics are obtained in the pyrolysis that is carried out at $1000{ }^{\circ} \mathrm{C}[49,54]$. The ${ }^{29} \mathrm{Si}$ MAS NMR spectrum of the polysiloxane microspheres that are heated for a longer time at this temperature is typical of a ceramic SiOC material (Scheme 5). The broad signals represent all silicon atoms being in the center of tetrahedra, which differ in the number of carbon and oxygen atoms at the tetrahedral corners. The signals are centered at following shifts (in ppm): -108 for $\mathrm{SiO}_{4}$ representing silica, -70 for $\mathrm{SiCO}_{3},-37$ for $\mathrm{Si}_{2} \mathrm{O}_{2},+1$ for $\mathrm{SiC}_{3} \mathrm{O}$ and -18 for $\mathrm{SiC}_{4}$ representing silicon carbide. The segregation of free carbon occurs during the ceramization process, already below $1000{ }^{\circ} \mathrm{C}[57,59]$. The aromatic $\mathrm{sp}^{2}$ carbon gives an intensive broad peak in the ${ }^{13} \mathrm{C}$ MAS NMR spectrum with a maximum of $\sim 130 \mathrm{ppm}$ [53]. This carbon forms disordered turbostratic domains that have a tendency to graffitization when heated to higher temperatures. This free carbon segregation makes the material black and is possibly the reason that the microspheres lose their porosity.

Further increase in temperature from 1000 to $1400{ }^{\circ} \mathrm{C}$ leads to separation of silica and silicon carbide nanodomains. The intensity of $\mathrm{SiO}_{4}$ and $\mathrm{SiC}_{4}$ tetrahedra increase at the cost of the mixed $\mathrm{SiC}_{\mathrm{n}} \mathrm{O}_{4-\mathrm{n}}(\mathrm{n}=1-3)$ tetrahedra. Although the chemical structure and morphology of polysiloxane microspheres undergo deep transformation during heating to $1400{ }^{\circ} \mathrm{C}$, they retain their spherical shape and their surfaces are not cracked [53, 60] (Figs. 7a-d).

The density of the ceramized polysiloxane microspheres increases significantly from $1.2 \mathrm{~g} / \mathrm{cm}^{3}$ at room temperature to $\sim 2.5 \mathrm{~g} / \mathrm{cm}^{3}$ at $1400{ }^{\circ} \mathrm{C}$. Their hardness and Young modulus values are very high as shown by studies of the indentation of a cross-section of single microspheres embedded in epoxy resin or in glass [61] (Table 2).

The microspheres ceramized at $1500{ }^{\circ} \mathrm{C}$ retain fully their integrity and spherical shapes; but, their surfaces are fractured as seen in SEM photographs (Figs. 8a, b). At this temperature two processes proceed intensively; e.g., further segregation of silica and silicon carbide (Eq. 10) and wellknown carbothermal reduction of silica [62] (Eq. 11).

$\mathrm{SiC}_{\mathrm{n}} \mathrm{O}_{4-\mathrm{n}} \rightarrow \mathrm{SiC}+\mathrm{SiO}_{2}$

$\mathrm{SiO}_{2}(\mathrm{~s})+\mathrm{Csp}^{2}(\mathrm{~s}) \rightarrow \mathrm{SiC}(\mathrm{s})+\mathrm{SiO}(\mathrm{g})+\mathrm{CO}(\mathrm{g})+\mathrm{CO}_{2}(\mathrm{~g})$

The ${ }^{29} \mathrm{Si}$ MAS NMR that is ceramized at $1500{ }^{\circ} \mathrm{C}$ shows two intensity-enhanced signals; segregated silica and segregated silicon carbide, while other signals are greatly reduced (Fig. 9a) [60]. The carbothermal reduction process leads to the formation of gaseous products, among them $\mathrm{SiO}$, which is the reason of the formation of macropores and cracks on the microspheres surfaces. In this reaction silica is reduced by the segregated aromatic carbon-forming silicon carbide. The decrease in silica is compensated by its simultaneous formation in the reaction as seen in Eq. 10. 

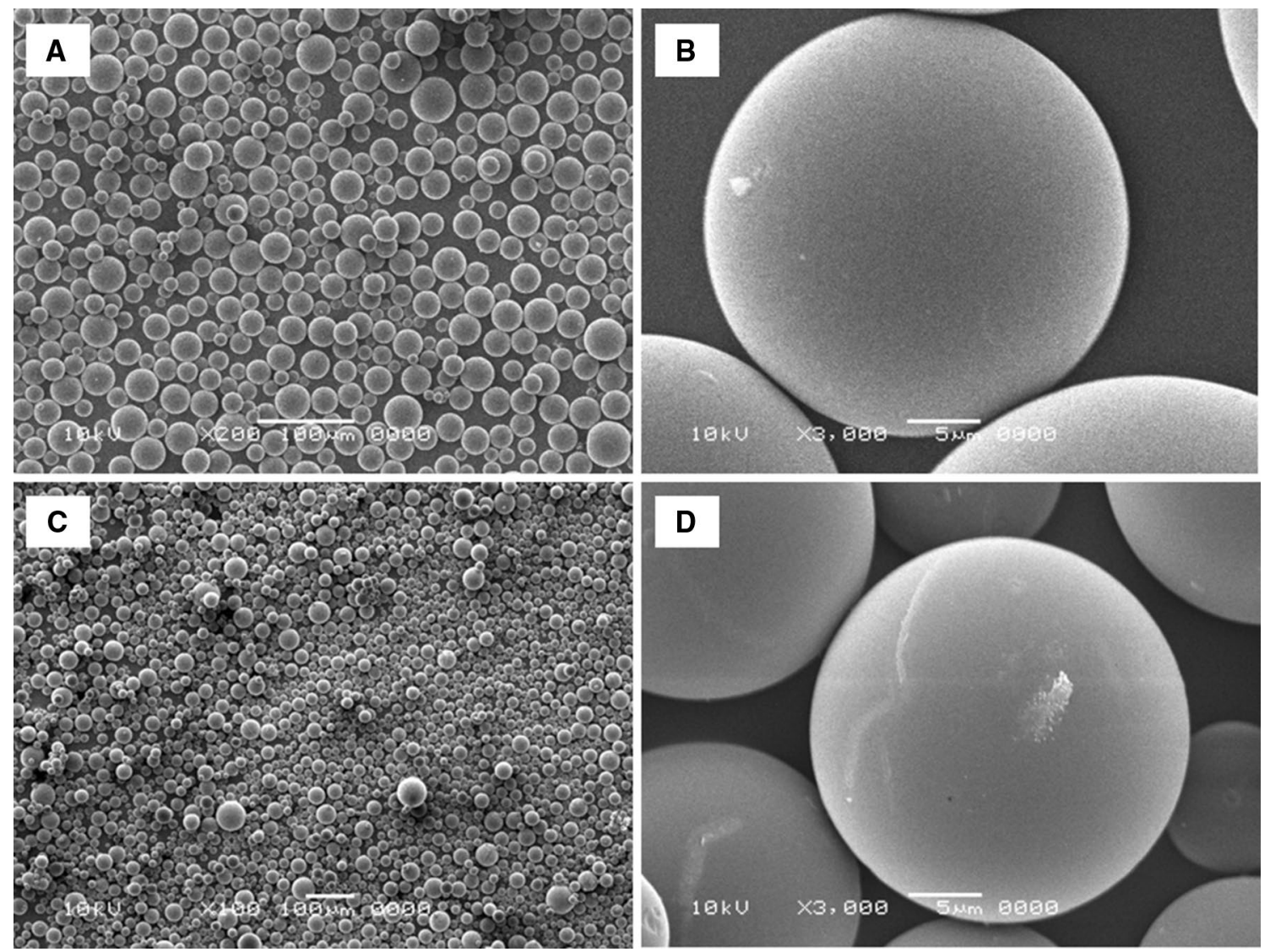

Fig. 7 SEM micrograms of polysiloxane microspheres heated at: a, b $1200{ }^{\circ} \mathrm{C}$ and $\mathbf{c}, \mathbf{d} 1400{ }^{\circ} \mathrm{C}, \mathbf{b}$, d were taken at higher enlargement

Table 2 Comparison of hardness and Young modulus of polysiloxane microspheres ceramized at various temperatures (data selected from Ref. [61])

\begin{tabular}{llll}
\hline $\begin{array}{l}\text { Temperature of } \\
\text { pyrolysis }\left({ }^{\circ} \mathrm{C}\right)\end{array}$ & Density $\left(\mathrm{g} / \mathrm{cm}^{3}\right)$ & Hardness $(\mathrm{GPa})$ & $\begin{array}{l}\text { Young } \\
\text { modulus } \\
(\mathrm{GPa})\end{array}$ \\
\hline 1000 & 2.19 & 10.6 & 120.4 \\
1200 & 2.26 & 12.4 & 115.4 \\
1400 & 2.47 & 12.0 & 112.4 \\
\hline
\end{tabular}

\section{Generation of Pores in the SiOC Ceramic Microspheres}

Mezo- and micropores may be generated in the SiOC ceramic materials by etching of the silica with a concentrated aqueous solution of HF [62, 63]. The effectiveness of the removal of silica from our ceramic microspheres by this procedure depends very much on the development of silica domains in the ceramic material. The etching with $\mathrm{HF}$ removes only a small part of the silica from the microspheres ceramized for $1 \mathrm{~h}$ at $1200{ }^{\circ} \mathrm{C}$ [60]. The porosity achieved is not high as seen in $\mathrm{N}_{2}$ adsorption studies (Table 3).

On the other hand, silica is almost fully removed from the microspheres ceramized for $1 \mathrm{~h}$ at $1500{ }^{\circ} \mathrm{C}$ by etching performed under the same conditions as seen from the comparison of ${ }^{29}$ Si MAS NMR spectra displayed in Fig. 9a, b, [60]. The volume of pores is high and their specific surface is over $1000 \mathrm{~m}^{2} / \mathrm{g}$. Heating for longer periods of time at $1500{ }^{\circ} \mathrm{C}$ leads to a decrease in the specific surface to about $700 \mathrm{~m}^{2} / \mathrm{g}$. At the same time the average diameter of pores and their volume increase (Table 3), which means that fewer micropores and more mezopores are formed. This observation allows us to conclude that small silica nanodomains have a tendency to disappear at the cost of the increase of larger domains when the material is heated for a longer time at $1500{ }^{\circ} \mathrm{C}$. 

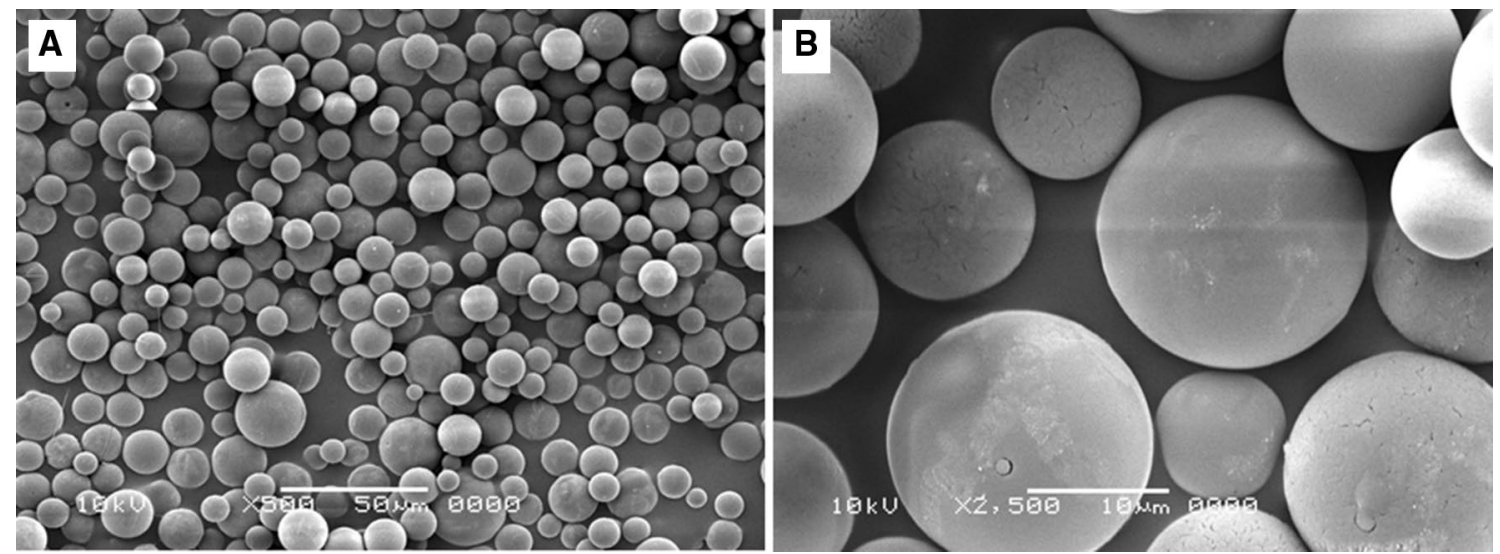

Fig. 8 SEM micrograms of polysiloxane microspheres ceramized at $1500^{\circ} \mathrm{C}$ : $\mathbf{a}$ in lower and $\mathbf{b}$ in higher enlargement

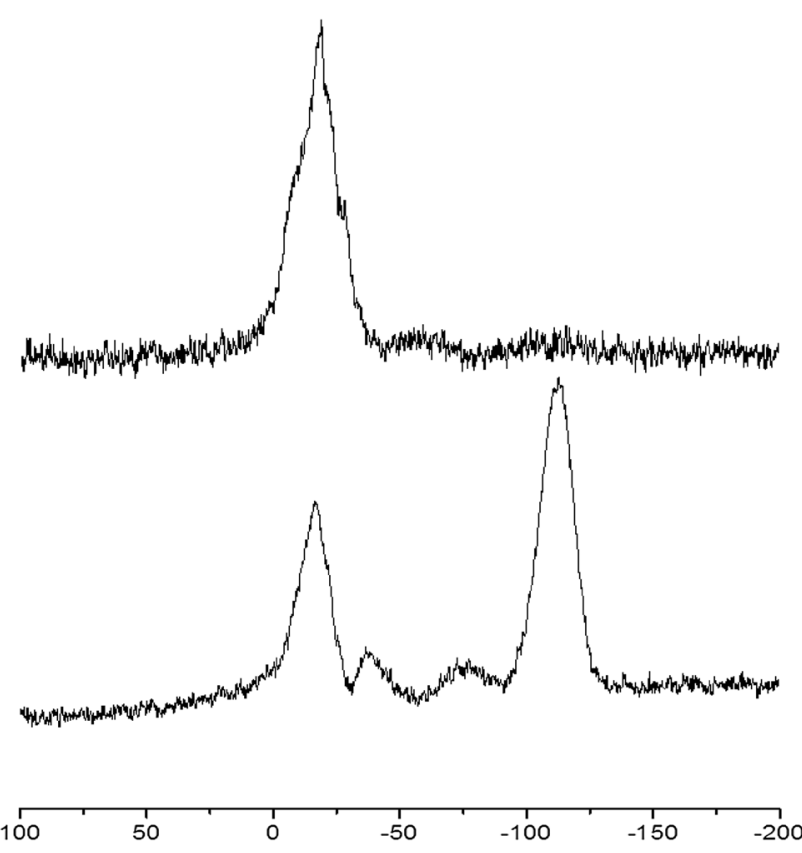

Fig. $9{ }^{29} \mathrm{Si}$ MAS NMR of microspheres: $\mathbf{a}$ before and $\mathbf{b}$ after etching with $\mathrm{HF}\left(1500^{\circ} \mathrm{C}\right)$

Table 3 Porosity of ceramic microspheres derived from polyhydromethylsiloxane pyrolized in various conditions

\begin{tabular}{llcll}
\hline $\begin{array}{l}\text { Temperature } \\
\text { of ceramiza- } \\
\text { tion }\left({ }^{\circ} \mathrm{C}\right)\end{array}$ & $\begin{array}{l}\text { Time of } \\
\text { heating } \\
(\mathrm{h})\end{array}$ & $\begin{array}{l}\text { Specific } \\
\text { surface area } \\
(\mathrm{SSA})\left(\mathrm{m}^{2} / \mathrm{g}\right)\end{array}$ & $\begin{array}{l}\text { Pore volume } \\
(\mathrm{V})\left(\mathrm{cm}^{3} / \mathrm{g}\right)\end{array}$ & $\begin{array}{l}\text { Pore size } \\
(\mathrm{Dav}) \\
(\mathrm{nm})\end{array}$ \\
\hline 1200 & 1 & 81 & 0.06 & 3.91 \\
1500 & 1 & 1094 & 0.34 & 3.17 \\
1500 & 5 & 738 & 0.59 & 3.98 \\
\hline
\end{tabular}

Data were selected from Ref. [60]

\section{Conclusions}

Aqueous emulsion processing of polyhydromethylsiloxane in the presence of $\operatorname{Pt}(0)$ Karstedt catalyst replaces partly the $\mathrm{SiH}$ bonds by silanol groups. The process described here allows for the substitution of $\mathrm{SiOH}$ groups with as much as $80 \% \mathrm{SiH}$ bonds in the polymer. The resulting polysiloxanes shows very interesting hydrophilic-hydrophobic properties. In addition, the $\mathrm{SiH}$ and $\mathrm{SiOH}$ reactive groups can be very easily modified. The hydrolysis of $\mathrm{SiH}$ takes place during the consolidation of microspheres and results in the cross-linking of the polymer by the hydrosililation of a diolefinic reactant with the $\mathrm{SiH}$ groups. The method provides multiple possibilities of manipulation with solvents, cross-linkers, additives and reaction parameters to generate microspheres that have various average sizes containing diverse numbers of silanol, hydrosilane and alkoxysilane groups to achieve a variety of cross-linking densities as well as structures containing bridges that link polymer chains. Macroporous spheroidal particles and core-shell capsules may be also formed. Chemical modification allows for the introduction of a variety of functional groups to the microspheres and fine-tunes their hydrophilic-hydrophobic properties. These polysiloxane microspheres are useful preceramic materials for the generation of silicon oxycarbide microspheres. In their ceramization processes carried out at temperatures $1000-1500{ }^{\circ} \mathrm{C}$ the spherical shape of the particles is retained. The additional step of the preceramic polymer cross-linking is not needed and a high yield of ceramic material is obtained. Highly porous structures of the formed ceramic microspheres may be developed by a $\mathrm{HF}$ etching process. 
Open Access This article is distributed under the terms of the Creative Commons Attribution 4.0 International License (http://creativeco mmons.org/licenses/by/4.0/), which permits unrestricted use, distribution, and reproduction in any medium, provided you give appropriate credit to the original author(s) and the source, provide a link to the Creative Commons license, and indicate if changes were made.

\section{References}

1. W. Liu, X.D. Chen, C. Selomulya, On the spray drying of uniform functional microparticles. Particuology 22, 1-12 (2015)

2. J.A. Bonham, M.A. Faers, J.S. van Duijneveldt, Non-aqueous microgel particles: synthesis, properties and applications. Soft Matter 10, 9384-9398 (2014)

3. J.K. Oh, R. Drumright, D.J. Siegwart, K. Matyjaszewski, The development of microgels/nanogels for drug delivery applications. Prog. Polym. Sci. 33, 448-477 (2008)

4. J. Guo, W. Yang, Ch. Wang, Magnetic colloidal supraparticles: design, fabrication and biomedical applications. Adv. Mater. 25, 5196-5214 (2013)

5. K. Saralidze, L.H. Koole, M.L.W. Knetsch, Polymeric microspheres for medical applications. Materials 3, 3537-3564 (2010)

6. M.J. Owen, in Silicon Containing Polymers, ed. by R.G. Jones, W. Ando, J. Chojnowski (Kluwer Academic Publishers, Dordrecht, 2000), pp. 213-231

7. Q. Tang, J.-R. Yu, L. Chen, J. Zhu, Z.-M. Hu, Poly (dimethyl siloxane)/poly (2-hydroxyethyl methacrylate) interpenetrating polymer network beads as potential capsules for biomedical use. Curr. Appl. Phys. 11, 945-950 (2011)

8. V. Carelli, S. Coltelli, G. Di Colo, E. Nannipieri, M.F. Serafini, Silicone microspheres for $\mathrm{pH}$-controlled gastrointestinal drug delivery. Int. J. Pharmaceut. 179, 73-83 (1999)

9. D. Giaume, M. Poggi, D. Casanova, G. Mialon, K. Lahlil, A. Alexandrou, T. Gacoin, J.-P. Boilot, Organic functionalization of luminescent oxide nanoparticles toward their application as biological probes. Langmuir 24, 11018-11026 (2008)

10. B. Liu, S. Cao, X. Deng, S. Li, O. Luo, Adsorption behavior of protein onto siloxane microspheres. Appl. Surf. Sci. 252, 7830$7836(2006)$

11. A. Buthe, A. Kapitain, W. Hartmeier, M.B. Ansorge-Schumacher, Generation of lipase-containing static emulsions in silicone spheres for synthesis in organic media. J. Mol. Catal. B 35, 93-99 (2005)

12. L. Bromberg, E.P. Chang, T.A. Hatton, A. Concheiro, B. Magarinos, C. Alvarez-Lorenzo, Bactericidal core-shell paramagnetic nanoparticles functionalized with poly(hexamethylene biguanide). Langmuir 27, 420-429 (2011)

13. Y. Motoyama, K. Mitsui, T. Ishida, H. Nagashima, Self-Encapsulation of homogeneous catalyst species into polymer gel leading to a facile and efficient separation system of amine products in the $\mathrm{Ru}$-catalyzed reduction of carboxamides with polymethylhydrosiloxane (PMHS). J. Am. Chem. Soc. 127, 13150-13151 (2005)

14. B. Heurtefeu, C. Bouilhac, E. Cloutet, D. Taton, A. Deffieux, H. Cramail, Polymer support of "single-site" catalysts for heterogeneous olefin polymerization. Prog. Polym. Sci. 36, 89-126 (2011)

15. S. Ma, W.Q. Liu, D. Yu, Z.F. Wang, Modification of epoxy resin with polyether-grafted-polysiloxane and epoxy-miscible polysiloxane particles. Macromol. Res. 18, 22-28 (2010)

16. W.-D. He, C.-T. Cao, C.-Y. Pan, Study of the preparation of silicone rubber particles with core-shell structure by seeded emulsion polymerization. Polym. Int. 39, 31-36 (1996)

17. X.Z. Kong, E. Ruckenstein, Core-shell latex particles consisting of polysiloxane-poly(styrene-methyl methacrylate-acrylic acid): preparation and pore generation. J. Appl. Polym. Sci. 73, 2235-2245 (1999)

18. H.-G. Wang, P. Chen, X.-M. Zheng, Studies on template synthesis method for fabrication of hollow microcapsules from diphenyldimethoxysilane monomer. Acta Chim. Sinica 64, 839-844 (2006)

19. C.I. Zoldesi, C.A. van Walree, A. Imhof, Deformable hollow hybrid silica/siloxane colloids by emulsion templating. Langmuir 22, 4343-4352 (2006)

20. J. Liu, S. Huang, D. Li, Vinyl functional polysiloxane microemulsion: preparation and characterization. Iranian Polym. J. 20, 825-834 (2011)

21. P. Yan, L.Y. Qiu, Preparation and characterization of polysiloxaneacrylate latexes with MPS-PDMS oligomer as macromonomer. J. Appl. Polym. Sci. 114, 760-768 (2009)

22. W. Fortuniak, J. Chojnowski, S. Slomkowski, P. Pospiech, J. Kurjata, Route to hydrophilic, hydrophobic and functionalized crosslinked polysiloxane microspheres. Polymer 54, 3156-3165 (2013)

23. B. Marciniec, H. Maciejewski, C. Pietraszuk, P. Pawluć, B. Marciniec, Hydrosilylation-a comprehensive review on recent advances, in Advances in silicon science, ed. by J. Matisons (Springer, Heidelberg, 2009), pp. 3-44

24. S. Slomkowski, W. Fortuniak, J. Chojnowski, P. Pospiech, U. Mizerska, Polysiloxane microcapsules, microspheres and their derivatives. Polimery 62, 499-508 (2017)

25. P. Pospiech, J. Chojnowski, U. Mizerska, W. Fortuniak, S. Slomkowski, Macroporous microspheres and microspheroidal particles from polyhydromethylsiloxane. Colloid Polym. Sci. 295, 939-944 (2017)

26. S. Kango, S. Kalia, A. Celli, J. Njuguna, Y. Habibi, R. Kumar, Surface modification of inorganic nanoparticles for development of organic-inorganic nanocomposites-a review. Prog. Polym. Sci. 38, 1232-1261 (2013)

27. S. Rubinsztajn, M. Cypryk, J. Chojnowski, Condensation of model linear siloxane oligomers possessing silanol and silyl chloride end groups. The Mechanism of silanol silylation by a chlorosilane in the presence of neutral nucleophiles. J. Organometal. Chem. 367, 27-37 (1989)

28. P. Pospiech, J. Chojnowski, U. Mizerska, G. Cempura, Platinum catalyst on polysiloxane microspheres with $\mathrm{N}$-chelating groups. J. Mol. Catal. A 424, 402-411 (2016)

29. P. Pospiech, J. Chojnowski, U. Mizerska, T. Makowski, K. Strzelec, N. Sienkiewicz, Polysiloxane microspheres functionalized with imidazole groups as a palladium catalyst support. Appl. Organomet. Chem. 30, 399-407 (2015)

30. U. Mizerska, R. Halasa, K. Turecka, J. Chojnowski, P. Pospiech, W. Fortuniak, S. Slomkowski, T. Makowski, W. Machnowski, P. Sowinski, Bacterial cell killing properties of silver-loaded polysiloxane microspheres. J. Mater. Sci. 53, 7125-7137 (2018)

31. W. Zawartka, P. Pospiech, M. Cypryk, A.M. Trzeciak, Palladium supported on aminopropyl-functionalized polymethylsiloxane microspheres: simple and effective catalyst for the SuzukiMiyaura C-C coupling. J. Mol. Catal. A 4407, 230-235 (2015)

32. W. Fortuniak, J. Chojnowski, A route to polysiloxanes with pendant imidazole groups. Polym. Bull. 38, 371-378 (1997)

33. H. Chen, L. Yuan, W. Song, Z. Wu, D. Li, Biocompatible polymer materials: role of protein-surface interactions. Prog. Polym. Sci. 33, 1059-1087 (2008)

34. U. Mizerska, W. Fortuniak, P. Pospiech, J. Chojnowski, S. Slomkowski, Gamma globulins adsorption on carbofunctional polysiloxane microspheres. J. Inorg. Organometal. Polym. Mater. 25, 507-514 (2015)

35. U. Mizerska, W. Fortuniak, P. Pospiech, A. Sobczak, J. Chojnowski, S. Slomkowski, Hydrophilic-hydrophobic properties of $\mathrm{SiOH}-$ loaded and modified polysiloxane microspheres and their 
interaction with $\gamma$-globulin. Polym. Adv. Technol. 26, 855-864 (2015)

36. M. Gosecka, S. Slomkowski, T. Basinska, Interactions of serum proteins and alkaline phosphatase with poly(styrene/ $\alpha$-tertbutoxy- $\omega$-vinylbenzyl-polyglycidol) microspheres with various surface concentrations of polyglycidol. Polym. Adv. Technol. 25, 1264-1272 (2014)

37. O. Ponta, R. Ciceo-Lucacel, A. Vulpoi, T. Radu, S. Simon, Molybdenum effect on the structure of $\mathrm{SiO}_{2}-\mathrm{CaO}-\mathrm{P}_{2} \mathrm{O}_{5}$ bioactive xerogels and on their interface processes with simulated biofluids. J. Biomed. Mater. Res. 102, 3177-3185 (2014)

38. J.J. Gray, The interaction of proteins with solid surfaces. Current Opin. Struct. Biol. 14, 110-115 (2004)

39. P. Aggarval, J.B. Hall, C.B. McLeland, M.A. Dobrovolskaia, S.E. McNeil, Nanoparticle interaction with plasma proteins as it relates to particle biodistribution, biocompatibility and therapeutic efficacy. Adv. Drug Deliv. Rev. 61, 428-437 (2009)

40. C. Ye, A. Chen, P. Colombo, C. Martinez, Ceramic microparticles and capsules via microfluidic processing of a preceramic polymer. J. R. Soc. Interface 7, S461-S473 (2010)

41. C. Vakifahmetoglu, M. Buldu, A. Karakuscu, A. Ponzoni, D. Assefa, G.D. Soraru, High surface area carbonous components from emulsion derived $\mathrm{SiOC}$ and their gas sensing behavior. J. Eur. Ceram. Soc. 35, 4447-4452 (2015)

42. M. Nangrejo, E. Bernardo, P. Colombo, U. Farook, Z. Ahmad, E. Stride, M. Edirisinghe, Electrohydrodynamic forming of porous ceramic capsules from a preceramic polymer. Mater. Lett. 63, 483-485 (2009)

43. V. Naglieri, P. Colombo, Ceramic microspheres with controlled porosity by emulsion-ice templating. J. Eur. Ceram. Soc. 37, 2559-2568 (2017)

44. W. Fortuniak, S. Slomkowski, J. Chojnowski, J. Kurjata, A. Tracz, U. Mizerska, Synthesis of a paraffin phase change material microencapsulated in a siloxane polymer. Colloid Polym. Sci. 291, 725-733 (2013)

45. B. Zgardzinska, M. Filipek, W. Fortuniak, P. Mroczek, Properties of n-eicosane-filled microcapsules with different morphology. Phase change materials studied by positron spectroscopy and complementary methods. Mater. Chem. Phys. 177, 79-91 (2016)

46. M. Delgado, A. Lazaro, J. Mazo, B. Zalba, Review on phase change material emulsions and microencapsulated phase change material slurries: materials, heat transfer studies and applications. Renew. Sust. Energ. Rev. 16, 253-273 (2012)

47. S. Mondal, Phase change materials for smart textiles-an overview. Appl. Therm. Eng. 28, 1536-1550 (2008)

48. A. Karaszewska, I. Kamińska, A. Nejman, B. Gajdzicki, W. Fortuniak, J. Chojnowski, S. Slomkowski, P. Sowinski, Thermalregulation of nonwoven fabrics by microcapsules of n-eicosane coated with a polysiloxane elastomer. Mater. Chem. Phys. 226, 204-213 (2019)

49. P. Colombo, G. Mera, R. Riedel, G.D. Soraru, Polymer-derived ceramics: 40 years of research and innovation in advanced ceramics. J. Amer. Ceram. Soc. 93, 1805-1837 (2010)
50. R. Riedel, G. Mera, R. Hauser, A. Klonczynski, Silicon-based polymer-derived ceramics: synthesis properties and applications-a review. J. Ceram. Soc. Jap. 114, 425-444 (2006)

51. V. Bakumov, M. Schwarz, E. Kroke, Emulsion processing and size control of polymer-derived spherical $\mathrm{Si} / \mathrm{C} / \mathrm{O}$ ceramic particles. Soft Mater. 4, 287-299 (2007)

52. W. Fortuniak, J. Chojnowski, S. Slomkowski, A. NyczykMalinowska, P. Pospiech, U. Mizerska, Solid ceramic SiCO microspheres and porous rigid siloxane microspheres from swellable polysiloxane particles. Mater. Chem. Phys. 155, 83-91 (2015)

53. W. Fortuniak, P. Pospiech, U. Mizerska, J. Chojnowski, S. Slomkowski, A. Nyczyk- Malinowska, R. Lech, M. Hasik, SiCO ceramic microspheres produced by emulsion processing and pyrolysis of polysiloxanes of various structures. Ceram. Int. 42, 11654-11665 (2016)

54. R.J.P. Corriu, D. Leclercq, P.H. Mutin, A. Vioux, Preparation and structure of silicon oxycarbide glasses derived from polysiloxane precursors. J. Sol-Gel. Sci. Technol. 8, 327-330 (1997)

55. G.D. Soraru, S. Modena, E. Guadagnino, P. Colombo, J. Egan, C. Pantano, Chemical durability of silicon oxycarbide glasses. J. Am. Ceram. Soc. 85, 1529-1536 (2002)

56. A. Saha, R. Raj, Crystallization maps for $\mathrm{SiCO}$ amorphous ceramics. J. Am. Ceram. Soc. 90, 578-583 (2007)

57. S. Martinez-Crespiera, E. Ionescu, H.-J. Kleebe, R. Riedel, Pressureless synthesis of fully dense and crack-free SiOC bulk ceramics via photo-crosslinking and pyrolysis of a polysiloxane. J. Eur. Ceram. Soc. 31, 913-919 (2011)

58. M. Adam, M. Wilhelm, G. Grathwohl, Polysiloxane derived hybrid ceramics with nanodispersed Pt. Microporous Mesoporous Mater. 151, 195-200 (2012)

59. H.J. Klebe, Y.D. Blum, SiOC ceramics with high excess free carbon. J. Eur. Ceram. Soc. 28, 1037-1042 (2008)

60. W. Fortuniak, P. Pospiech, U. Mizerska, J. Chojnowski, S. Slomkowski, A. Nyczyk-Malinowska, A. Wojteczko, E. Wisla-Walsh, M. Hasik, Generation of meso- and microporous structures by pyrolysis of polysiloxane microspheres and by HF etching of SiOC microspheres. Ceram. Int. 44, 374-383 (2018)

61. W. Szymański, S. Lipa, W. Fortuniak, J. Chojnowski, P. Pospiech, U. Mizerska, S. Slomkowski, A. Nyczyk-Malinowska, M. Hasik, Silicon oxycarbide (SiOC) ceramic microspheres-structure and mechanical properties by nanoindentation studies. Ceram. Int. 45, 11946-11954 (2019)

62. L. Duan, Q. Ma, Effect of pyrolysis temperature on the pore structure evolution of polysiloxane-derived ceramics. Ceram. Int. 38, 2667-2671 (2012)

63. S. Dire, V. Tagliazucca, L. Salvadori, G.D. Soraru, Preparation of dense and porous silicon oxycarbide submicrometer-sized spheres using a modified Stöber process. J. Am. Ceram. Soc. 94, 3819-3824 (2011)

Publisher's Note Springer Nature remains neutral with regard to jurisdictional claims in published maps and institutional affiliations. 